\title{
UPAYA PENINGKATAN KESADARAN KESEHATAN GIGI DAN MULUT BAYI DAN BALITA MELALUI SEKOLAH IBU: BALITA SEHAT DAN BERKUALITAS DENGAN GIGI YANG SEHAT
}

\author{
Arya Adiningrat ${ }^{1)}$, Wustha Farani ${ }^{2)}$ \\ ${ }^{1}$ Program Studi Kedokteran Gigi, Fakultas Kedokteran dan Ilmu Kesehatan, \\ Universitas Muhammadiyah Yogyakarta \\ ${ }^{2}$ Program Studi Kedokteran Gigi, Fakultas Kedokteran dan Ilmu Kesehatan, \\ Universitas Muhammadiyah Yogyakarta \\ E-mail: adiningrat@umy.ac.id
}

\begin{abstract}
Oral health problems are still become problem among Indonesian societies. According to the Basic Health Research data in 2018, oral health problems are still high, up to $57.6 \%$. Oral health problems could be critical issues when occurring in infancy toward proper growth and development. Most of society and mothers in particular do not understand correctly how to provide proper care in toddler's oral health. The Mother School of 'Bunda Sholihah' is a local community group whose having concern in increasing mother capacity for child development. This activity was designed to train the mothers and empower the active role in educating others in the community. Both training and educational practices were performed. Training which has been carried out consists of education in lectures, two-way discussions and role analogies, followed by giving the assignments. The number of participants in this activity was up to 45 members from the Bunda Sholihah community in Kasihan district with participation rate reached $75.5 \%$. This activity was carried out in groups, for once a week in 4 weeks activity. Results of the program showed a significant increase in mother knowledge's level $(p<0.05)$ including mother's personal motivation regarding the importance of early dental examination in toddler.
\end{abstract}

Keywords: Early dental examination; Oral health problem; Mother school; Toddler age.

\section{PENDAHULUAN}

Kesehatan gigi dan mulut seringkali masih belum merupakan prioritas bagi kesehatan masyarakat. Sementara proporsi masalah kesehatan gigi dan mulut masih sangat tinggi yaitu $57.6 \%$ (RISKESDAS,
2018). Proporsinya yang cukup tinggi tersebut masih ditambah dengan kecilnya prosentasi penderita yang mendapatkan perawatan medis yaitu hanya sekitar $10.2 \%$. Hal ini akan menimbulkan dampak yang besar di masyarakat. 


\section{GEMASSIKA: Jurnal Pengabdian Kepada Masyarakat}

Vol. 4 No. 1 Mei 2020

Permasalahan lain adalah masih rendahnya motivasi masyarakat dalam berbagai aktivitas yang berkaitan dengan masalah kesehatan gigi. Menjaga kesehatan gigi dengan perawatan dan pemeriksaan rutin ke tenaga kesehatan, belum rutin dilaksanakan. Masyarakat cenderung akan datang, jika sudah dalam kondisi sakit. Rendahnya motivasi tersebut dipengaruhi oleh kurangnya pengetahuan masyarakat terkait dengan masalah kesehatan. Masyarakat sangat membutuhkan bekal pengetahuan yang benar tentang masalah kesehatan gigi sehingga akan memiliki sikap dan perilaku yang benar dalam menjaga kesehatan gigi (DIRJEN BUK, 2012).

Menjaga kesehatan gigi seharusnya dimulai sejak masa Balita. Ibu Balita memiliki peran penting dalam penjagaan kesehatan gigi Balita yang akan mempengaruhi kesehatan anak pada masa selanjutnya (Mouth Healthy, 2019). Kerusakan gigi di masa gigi susu bisa mengganggu pertumbuhan gigi dewasanya termasuk arah tumbuh dan posisi gigi dewasanya. Infeksi kronis pada gigi susu juga dapat mengganggu tumbuh kembang rahang dan gigi dewasa (Scully dkk., 1994). Pola diet dan konsumsi bahan-bahan kimia dan obat-obatan tertentu bisa mempengaruhi kualitas struktur gigi dewasa (Begzati dkk.,
2015). Kelainan bentuk dan struktur gigi susu lebih disebabkan oleh sebab-sebab yang terjadi pada masa kehamilan. Kerusakan masif gigi gigi susu kronis akan akan berdampak pada asupan gizi-nutrisi pada masa tumbuh kembang. Kerusakan gigi hingga kematian gigi pada masa gigi susu, bisa memicu fokal infeksi, kejadian infeksi pada anak apalagi balita akan menyebabkan usia dini harus terpapar banyak obat-obatan yang seharusnya bisa diminimalisir (Dooley, dkk., 2016 dan ADA, 2012). Sedemikian pentingnya menjaga kesehatan gigi Balita, agar dapat melindungi kesehatan anak sehingga tidak berdampak pada kualitas pertumbuhan dan perkembangannya. Peran aktif masyarakat khususnya kaum ibu dalam menjaga kesehatan gigi Balita sangat dibutuhkan. Para ibu harus memiliki pengetahuan yang benar tentang perawatan gigi Balita, menjaga gigi tetap sehat, mencegah gangguan pada gigi dan segera mengupayakan pertolongan kepada tenaga kesehatan jika terjadi gangguan.

Sekolah Ibu Bunda Sholihah merupakan organisasi masyarakat di kabupaten Bantul, membuat program-program untuk membekali para ibu muda dalam mengoptimalkan tumbuh kembang anak. Kegiatan ini dirancang untuk membekali anggota dan pengurus Sekolah Ibu "Bunda Sholihah" agar memiliki pengetahuan 
dan perilaku yang benar dalam menjaga kesehatan balita serta mengedukasikan pada masyarakat luas di wilayahnya. Sekolah Ibu "Bunda Sholihah" memiliki tujuan untuk memberikan bekal kepada para ibu muda dalam mendidik anak menjadi sholih, sehat, cerdas dan berkualitas. Sekolah Ibu "Bunda Sholihah" telah berdiri sejak 1 tahun yang lalu. Di usianya yang masih muda, Sekolah Ibu "Bunda Sholihah" telah banyak melaksanakan kegiatan untuk mewujudkan visinya, diantaranya adalah pertemuan rutin yang dilaksanakan minimal sebulan sekali dengan berbagai variasi kegiatan antara lain ceramah, diskusi, problem solving dan tugastugas praktek yang di laksanakan di keluarga serta dievaluasi secara rutin bersama-sama. Sekolah Ibu "Bunda Sholihah" didampingi oleh ustadz dan tenaga kesehatan yang tinggal di wilayah yang sama sebagai pembina, sehingga lebih intensif dalam pendampingan. Akan tetapi, sekolah ibu "Bunda Sholihah" hingga saat ini belum pernah mengadakan ataupun memperoleh pembinaan dan edukasi terkait kesehatan gigi dan mulut sebelumnya. Hal ini juga mungkin sangat dipengaruhi oleh masih sangat kurangnya kepedulian serta kesadaran masyarakat khususnya ibu-ibu dengan balita terhadap kesehatan gigi dan mulut, walaupun sekolah ibu "Bunda Sholihah" memiliki potensi yang besar untuk dapat dibina dan diedukasi secara berkesinambungan. Oleh karena itu, pemberdayaan melalui pembinaan sekolah ibu "Bunda Sholihah" ini diharapkan mampu meningkatkan efektivitas upaya pembinaan khususnya kepada para ibu yang memiliki peranan penting dalam melakukan upayaupaya pencegahan dini dari penyakit serta kelainan gigi dan mulut, sehingga kondisi kelainan serta penyakit yang berhubungan dengan kesehatan gigi dan mulut dapat lebih dicegah atau minimal berkurang tingkat keparahannya.

\section{MASALAH, TARGET, DAN LUARAN}

Berbagai kegiatan telah dilaksanakan oleh Sekolah Ibu "Bunda Sholihah" dalam mendukung program pemerintah di bidang kesehatan trutama kesehatan ibu dan Balita. Pertemuan secara rutin telah dilaksanakan dalam upaya peningkatan pengetahuan dan keterampilan para ibu dalam mendampingi tumbuh kembang Balita secara optimal. Berbagai pembekalan yang telah dilaksanakan adalah pemberian edukasi akan kesehatan gigi dan mulut bagi ibu agar dapat mendampingi Balita dalam mengaplikasikan tindakan-tindakan pencegahan sedini mungkin. Pembekalan akan pengetahuan 


\section{GEMASSIKA: Jurnal Pengabdian Kepada Masyarakat}

Vol. 4 No. 1 Mei 2020

terhadap kesehatan umum secara rutin juga telah diberikan oleh tenaga kesehatan sebagai narasumber. Namun demikian, pembekalan pengetahuan yang khusus tentang kesehatan gigi, belum pernah dilaksanakan. Ibu Balita membutuhkan pelatihan untuk meningkatkan pengetahuan dan keterampilannya dalam merawat kesehatan gigi balitanya serta bisa melakukan promosi, edukasi secara luas ke masyarakat. Berdasarkan analisis situasi di atas, maka dapat diketahui permasalahan mitra adalah:

1. Kurangnya pengetahuan anggota dan pengurus Sekolah Ibu "Bunda Sholihah" tentang kesehatan gigi Balita.

2. Kurangnya keterampilan anggota dan pengurus Sekolah Ibu "Bunda Sholihah" tentang kesehatan gigi Balita.

3. Kurangnya pengetahuan masyarakat tentang kesehatan gigi Balita.

4. Kurangnya keterampilan masyarakat tentang kesehatan gigi Balita.

Pengusul kegiatan PKM ini merupakan tim di bidang kesehatan khususnya di bidang kesehatan gigi dan mulut yang memiliki perhatian pada kesehatan gigi bayi dan balita. Tim pengabdian berharap dapat menjawab permasalahan dan kebutuhan yang dihadapi yayasan mitra dalam kaitannya terhadap perspektif kesehatan gigi bayi dan balita sebagai sebuah investasi tumbuh kembang yang lebih baik. Tim pelaksana kegiatan pengabdian ini membekali anggota dan pengurus Sekolah Ibu "Bunda Sholihah" dengan pengetahuan yang berkaitan dengan perkembangan normal gigi balita, cara perawatan gigi balita, mengenali masalah kesehatan gigi balita, penanganan masalah kesehatan gigi balita. Tim pelaksana program juga menyusun modul yang akan menjadi pegangan bagi para ibu dalam melakukan perawatan sejak dini bagi keluarga serta menjadi upaya pencegahan yang investatif.

Program ini menawarkan solusi untuk meningkatan pengetahuan dan keterampilan anggota dan pengurus Sekolah Ibu "Bunda Sholihah" dalam upaya mengoptimalkan tumbuh kembang Balita melalui peningkatan kesehatan gigi Balita. Program ini juga akan membekali anggota dan pengurus Sekolah Ibu "Bunda Sholihah" untuk melakukan edukasi masalah kesehatan gigi Balita kepada masyarakat luas. Solusi dapat dirinci sesuai dengan setiap permasalahan sebagai berikut:

1. Kurangnya pengetahuan anggota dan pengurus Sekolah Ibu "Bunda Sholihah" tentang kesehatan gigi Balita. Solusi yang ditawarkan adalah penyusunan dan penyediaan modul yang 
bagi anggota dan pengurus Sekolah Ibu "Bunda Sholihah" yang berisi materi tentang: 1). Perkembangan normal gigi Balita, 2). Cara perawatan gigi balita, 3). Mengenali masalah kesehatan gigi Balita, 4). Penanganan masalah kesehatan gigi Balita.

2. Kurangnya keterampilan anggota dan pengurus Sekolah Ibu "Bunda Sholihah" tentang kesehatan gigi Balita

3. Solusi yang ditawarkan adalah pelatihan modul yang telah disusun. Dengan pelatihan diharapkan para anggota dan pengurus Sekolah Ibu "Bunda Sholihah" siap untuk melaksanakan untuk Balitanya dan siap untuk melakukan edukasi kepada masyarakat.

4. Kurangnya pengetahuan masyarakat tentang madalah kesehatan gigi Balita Solusi yang ditawarkan adalah melakukan edukasi kepada masyarakat yang dilakukan oleh anggota dan pengurus Sekolah Ibu "Bunda Sholihah" yang telah mengikuti pelatihan dalam program PKM ini.

5. Kurangnya pengetahuan masyarakat tentang madalah kesehatan gigi Balita Solusi yang ditawarkan adalah melakukan edukasi kepada masyarakat yang dilakukan oleh anggota dan pengurus Sekolah Ibu "Bunda Sholihah" yang telah mengikuti pelatihan dalam program PKM ini.

Hasil dari program pengabdian masyarakat ini diharapkan memperoleh hasil berupa peningkatan pengetahuan, motivasi dan peran aktif anggota dan pengurus Sekolah Ibu "Bunda Sholihah" dalam upaya kesehatan gigi Balita di keluarga maupun di masyarakat sejak dini.

Tabel 1. Target Evaluasi Kegiatan

\begin{tabular}{|l|l|}
\hline No & Materi evaluasi \\
\hline 1. & Modul kesehatan gigi balita Bagi Ibu \\
\hline 2. & $\begin{array}{l}\text { Peningkatan pengetahuan peserta ten- } \\
\text { tang kesehatan gigi balita }\end{array}$ \\
\hline 3. & Video dokumentasi kegiatan \\
\hline 4. & Diseminasi hasil pengabdian \\
\hline
\end{tabular}

\section{METODE PELAKSANAAN}

Metode kegiatan dalam pengabdian ini adalah pelatihan dan praktek. Kegiatan yang dilaksanakan dalam pelatihan adalah ceramah (materi dari narasumber), diskusi dua arah, bermain peran dalam kelompok, praktek.

Peserta kegiatan adalah anggota dan pengurus Sekolah Ibu "Bunda Sholihah" sebanyak 50 orang dengan kriteria:

1. Memiliki Balita

2. Anggota dan pengurus Sekolah Ibu "Bunda Sholihah" 
3. Bersedia ikut dalam pelaksanaan keseluruhan kegiatan

4. Bertempat tinggal di wilayah Bantul

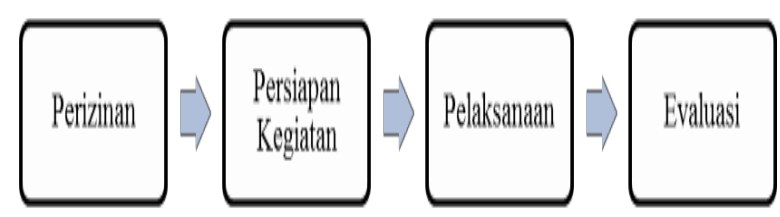

Gambar 1. Skema Kegiatan

Kegiatan dilaksanakan dalam 4 tahap yaitu:

\section{Perizinan}

Perijinan diajukan kepada Pemda Bantul, pemerintahan desa setempat.

2. Persiapan Kegiatan

Persiapan yang dilakukan adalah:

A. Seleksi peserta pelatihan berdasarkan kriteria oleh tim pengabdian.

B. Penilaian awal pengetahuan ibu tentang kesehatan gigi Balita dengan kuestioner sebelum dilakukan pelatihan.

C. Persiapan modul, buku kegiatan dan sarana prasarana lainnya.

D. Persiapan tempat pelaksanaan kegiatan pelatihan.

3. Pelaksanaan

Kegiatan pengabdian ini dilaksanakan melalui beberapa pendekatan yang dilakukan secara terpadu antara pelatihan, penyuluhan atau edukasi, diskusi interaktif hingga penjaringan feedback dan assessment lapangan dengan rincian sebagai berikut:

A. Pelatihan dilakukan dalam kegiatan kelompok (group) yang masingmasing terdiri dari 10 orang.

B. Kegiatan dilaksanakan seminggu 1 kali selama 4 minggu dengan durasi 60-90 menit.

C. Narasumber adalah tim pengabdian.

D. Pelatihan menggunakan modul Kesehatan Gigi Balita yang disusun oleh tim pengabdian terdiri dari: 1). Perkembangan normal gigi Balita, 2). Cara perawatan gigi balita, 3). Mengenali masalah kesehatan gigi Balita, 4). Penanganan masalah kesehatan gigi Balita.

E. Praktek perawatan gigi Balita dalam keluarga oleh peserta dimonitoring dan evaluasi oleh tim pengabdian dalam buku kegiatan.

F. Praktek edukasi masalah kesehatan gigi Balita di masyarakat oleh peserta dimonitoring dan evaluasi oleh tim pengabdian dalam buku kegiatan. 
4. Evaluasi

Output yang akan dinilai adalah terbentuknya kelompok ibu anggota dan pengurus Sekolah Ibu "Bunda Sholihah" yang peduli terhadap kesehatan gigi Balita, peningkatan pengetahuan dan keterampilan dalam kesehatan gigi Balita dan peningkatan pengetahuan dan keterampilan dalam edukasi kesehatan gigi Balita. Penilaian dilakukan di akhir program.

\section{HASIL PEMBAHASAN}

Target pencapaian peningkatan pengetahuan ibu-ibu peserta sekolah ibu Bunda Sholihah pada akhir dari rangkaian kegiatan pengabdian ini telah mengalami peningkatan yang cukup bermakna. Hal ini ditandai dengan meningkatnya jumlah peserta yang mengalami peningkatan pengetahuan akan kesehatan gigi dan mulut bayi-balita sebanyak $73.5 \%$ dari keseluruhan peserta sekolah ibu. Capaian peningkatan tingkat pengetahuan lebih dari 70\% peserta kegiatan ini menunjukkan keberhasilan upaya edukasi secara terpadu yang hanya dilakukan dalam 4 kali pertemuan tatap muka secara intensif. Selain dari intensifitas dalam setiap tatap muka yang dilakukan, kami juga mengevaluasi teknis penyuluhan yang kami lakukan pada setiap kegiatan tatap muka di sekolah ibu "Bunda Sholihah", diantaranya adalah pengupayaan penyampaian dalam suasana yang santai dan menggunakan media yang seimbang antara audio dan juga visual berupa foto dan gambar. Selain dari hasil jumlah peserta yang mengalami peningkatan pengetahuan akan perawatan dan kesehatan gigi dan mulut bayi-balita, kami juga mendapati sekitar $17.6 \%$ peserta yang tidak mengalami perubahan tingkat pengetahuan dan $8.8 \%$ peserta yang justru mengalami penurunan tingkat pengetahuannya. Adanya peserta yang cenderung tidak mengalami perubahan tingkat pengetahuan nya bahkan ada yang menurun pasca dilaksanakannya program ini kemungkinan dipengaruhi oleh faktor motivasi internal diri yang memang kurang. Hal ini dapat diamati secara sepintas bahwa tidak semua peserta mengikuti program secara keseluruhan atau lengkap, dan ditambah lagi dengan kami temui adanya peserta yang di awalnya ada akan tetapi di akhir-akhirnya tidak meneruskan keikutsertaannya, begitu pula yang terjadi sebaliknya juga ada. Variasi ini memang masih menjadi kendala serta tantangan kami tersendiri, mengingat memang masih banyak diantara masyarakat di Indonesia yang masih 
sulit melihat urgensi kesehatan gigi dan mulut itu sendiri sebagai suatu bentuk investasi kesehatan tubuh di masa depan.

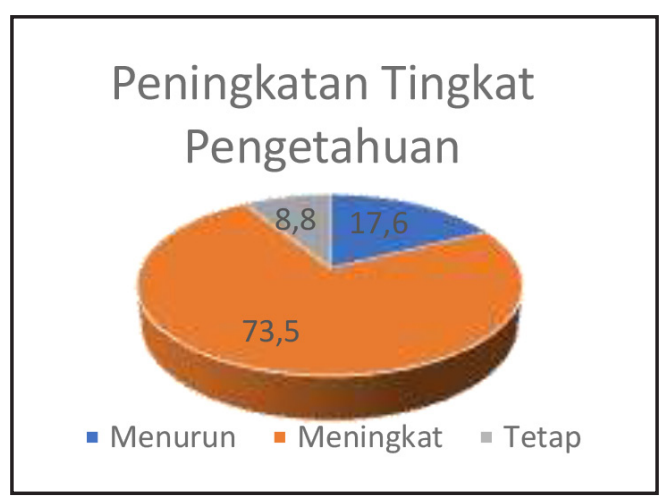

Grafik 1. Grafik pencapaian program

Selain dari upaya evaluasi program secara kualitatif dan persepsional, kami juga melakukan pre-test dan post-test untuk mengetahui tingkat pengetahuan ibu-ibu balita terhadap kesehatan gigi. Hasil rerata untuk pre-test sebesar 5.088 dan rerata posttest 6.735. Disini terdapat perbedaan yang bermakna antara nilai rerata pre-test dan nilai post-test $(\mathrm{p}<0.05)$ serta mengalami peningkatan rerata tingkat pengetahuan ibu-ibu balita peserta kegiatan pelatihan. Kebermaknaan perbedaan hasil nilai pretest dan post-test yang didapatkan ini juga menunjukkan efektivitas program ini secara kuantitatif.
Tabel 2.

Perhitungan statistik uji pengetahuan ibu-ibu sebelum dan sesudah.

\begin{tabular}{|c|c|c|}
\hline & & $\begin{array}{c}\text { Pair } 1 \\
\text { pre-test }- \text { post-test }\end{array}$ \\
\hline \multicolumn{2}{|l|}{ Mean } & -1.6471 \\
\hline \multicolumn{2}{|l|}{ Std Deviation } & 1.4540 \\
\hline \multicolumn{2}{|l|}{ Std Error } & 0.2494 \\
\hline \multirow{2}{*}{$\begin{array}{l}95 \% \\
\text { Confidence } \\
\text { Interval of the } \\
\text { Difference }\end{array}$} & Lower & -2.1544 \\
\hline & Upper & -1.1397 \\
\hline \multicolumn{2}{|l|}{$\mathrm{t}$} & -6.605 \\
\hline \multicolumn{2}{|l|}{ df } & 33 \\
\hline \multicolumn{2}{|l|}{ Sig. (2-tailed) } & 0.000 \\
\hline
\end{tabular}

Tingkat partisipasi serta keaktifan dari peserta sekolah ibu ini juga cukup tinggi, hal ini dapat ketahui melalui konsistensi kehadiran peserta sekolah ibu yang mencapai $75.5 \%$. Konsistensi ini tergambarkan melalui kehadiran peserta program yang senantiasa hadir sejak pertemuan pertama hingga pertemuan terakhir. Walaupun juga terdapat beberapa peserta yang hadir di awal program namun tidak hadir pada akhir program begitu pula sebaliknya (tidak hadir pada awal program namun hadir di akhir program) sebanyak $24.5 \%$ dari total keseluruhan partisipasi. Hal ini juga sejalan dengan telaah yang dilakukan sebelumnya bahwasanya kesiapan dan motivasi dari peserta penyuluhan dapat menjadi modal penting yang sangat mendukung keberhasilan proses pembinaan maupun penyuluhan di bidang kesehatan 
disamping jumlah kehadiran peserta secara fisik (Nakre \& Harikiran, 2013). Tanpa adanya motivasi internal atau diri yang kuat dari masing-masing peserta pembinaan maupun penyuluhan kesehatan akan sangat memberikan pengaruh terhadap kurang optimalnya program pembinaan ataupun penyuluhan pada umumnya. Oleh karena hal tersebut, maka menjadi penting dalam mendukung keberhasilan program untuk dapat menyelenggarakan upaya transfer materi dan pengetahuan dengan cara yang lebih dinamis, interaktif serta sesuai dengan kondisi peserta pada waktu pelaksanaan.

Pada peserta yang mengalami peningkatan tingkat pengetahuan terhadap kesehatan gigi dan mulut bayi-balita sebesar $73.5 \%$ dari keselurahan peserta di atas, memiliki hasil perolehan rerata nilai meningkat sebesar $20 \%$ hingga $40 \%$ dari total maksimal perolehan nilai (yang diperoleh dari sebelum dan sesudah mengikuti program sekolah ibu ini). Peningkatan tingkat pengetahuan ini tidak lepas dari dukungan partisipasi yang aktif serta interaktif dari peserta kegiatan selama program berlangsung. Sedangkan $8.8 \%$ peserta yang mengalami penurunan dalam perolehan nilai pre- dan post-test, keseluruhannya hanya menurun sebesar 10\% dari maksimal perolehan nilai. Adanya penurunan ini dimungkinkan pula disebabkan oleh karena kesalahpahaman peserta sekolah ibu namun tidak melakukan klarifikasi dan penjelasan lebih lanjut. Sedangkan kondisi $17.6 \%$ peserta yang tidak mengalami perubahan tingkat pengetahuan dari sebelum hingga setelah program ini berlangsung dapat dipengaruhi oleh beberapa kondisi teknis di lapangan seperti diantaranya kurang optimalnya partisipasi oleh karena memang dalam pelaksanaan program banyak peserta yang cukup disibukan dengan anak-anaknya (yang juga turut serta dalam program ini) dan juga kurang maksimalnya transfer informasi yang kami lakukan secara teknis di lapangan pada saat kegiatan program berlangsung.
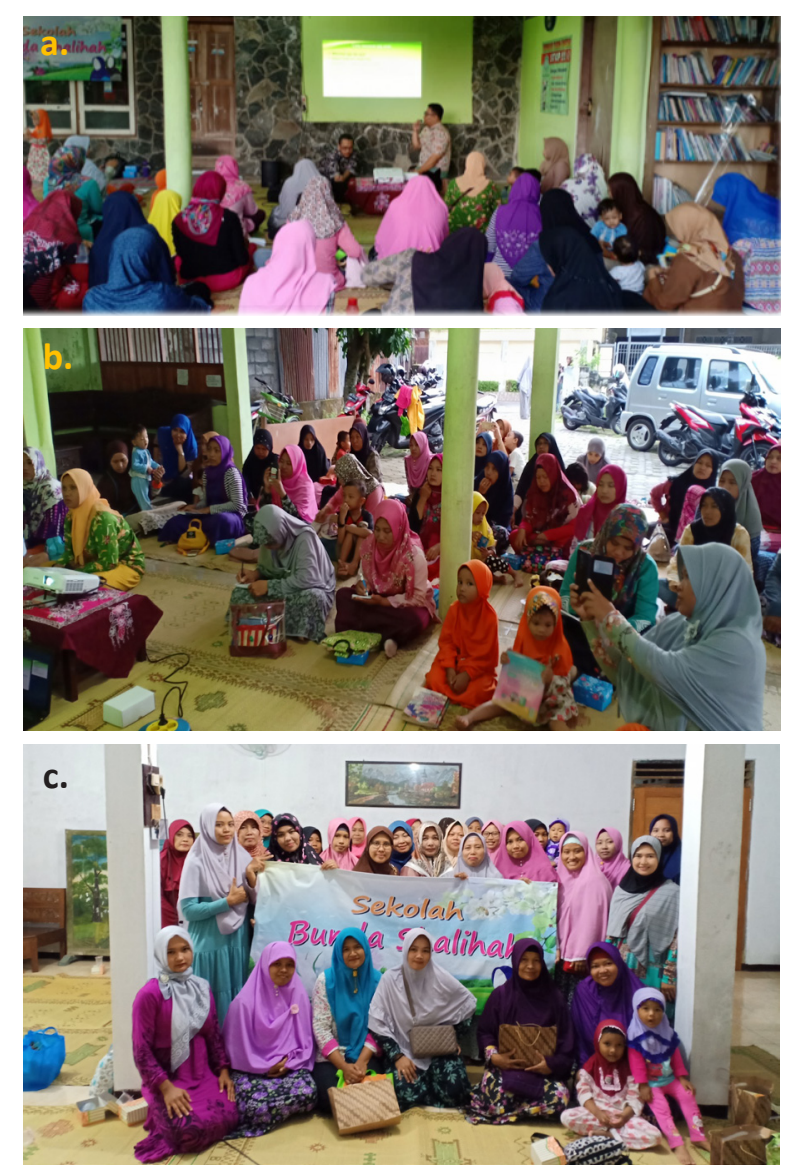

Gambar 2. Kegiatan pembinaan 
(a. Gambaran dinamisasi pembinaan menggunakan visualisasi dan suasana informal, b. Suasana pembinaan santai dari para ibu yang membawa serta anak-anak, c. Penutupan kegiatan pengabdian pada sekolah ibu "Bunda Sholihah").

Bentuk luaran yang telah kami wujudkan dari program pengabdian masyarakat bersama kelompok mitra yayasan bunda solihah dalam sekolah ibu ini antara lain berupa buku saku pedoman kesehatan gigi dan mulut bayibalita dan video dokumentasi kegiatan yang telah kami publikasikan melalui media massa (sosial media) youtube melalui link: https:// www.youtube.com/watch?v=B3n58ozXvIk.
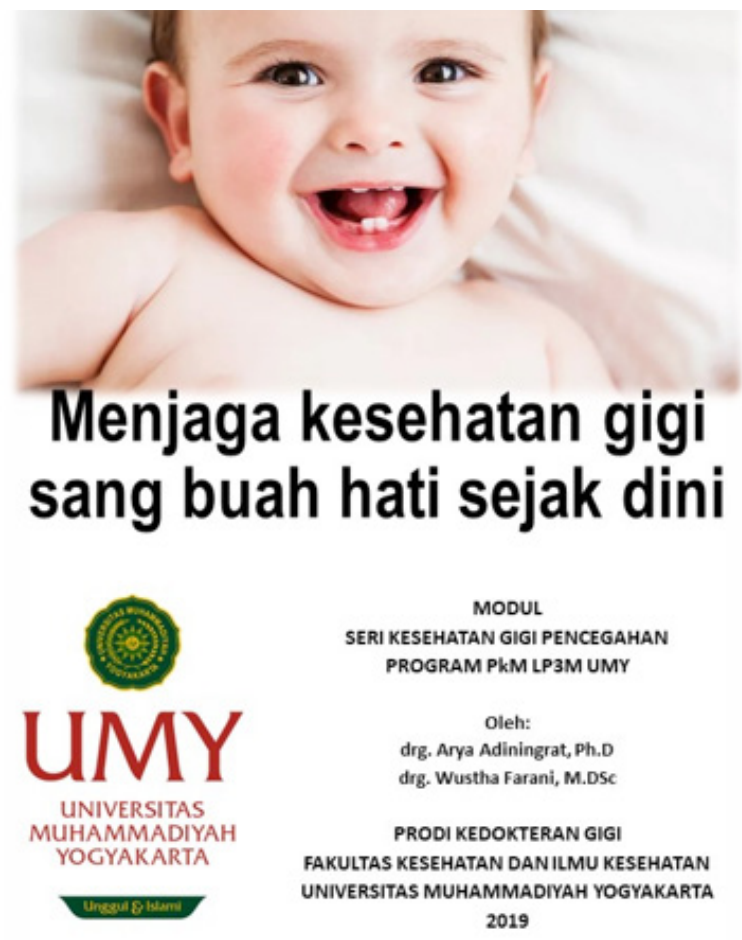

Gambar 3.

Modul Buku Pembinaan dan Edukasi yang diberikan kepada peserta sekolah ibu

"Bunda Sholihah".

\section{KESIMPULAN DAN SARAN}

Pada pelaksanaan program pengabdian kepada masyarakat bersama dengan kelompok mitra yayasan Bunda Sholihah ini dapat disimpulkan bahwa secara umum terdapat peningkatan tingkat pengetahuan terhadap kesehatan gigi dan mulut bayibalita secara bermakna. Capaian ini pula membuktikan adanya dukungan nyata dari mayoritas ibu-ibu dalam sekolah ibu "Bunda Sholihah" serta antusiasme yang cukup tinggi untuk mau berubah dan mengembangkan diri untuk kebaikan generasi anak muda masa depan. Oleh karena program ini merupakan program pengenalan yang relatif baru bersifat umum dan awal dalam rangka upaya preventif-pencegahan penyakit gigi dan mulut sedini mungkin, diharapkan program ini dapat ditindak lanjuti dengan upaya dan pendekatan-pendekatan yang lebih aplikatif serta nyata secara terpadu seiring dengan peningkatan tingkat pengetahuan ibu terkait kesehatan gigi-mulut bayi dan balita, sehingga peningkatan kondisi sehat gigimulut bayi dan balita ini dapat meningkat. Upaya serta pendekatan yang lebih nyata dan aplikatif ini sangat perlu dilakukan sebagai langkah nyata upaya penjagaan sekaligus peningkatan kesadaran ibu-ibu anggota dan pengurus yayasan Bunda Sholihah agar dapat berpartisipasi secara aktif dalam mewujudkan bayi dan balita sehat berkualitas masa depan. 


\section{DAFTAR PUSTAKA}

American Dental Association, 2012, Primary Tooth Development, dilihat 6 Maret 2019,http://www.mouthhealthy.org/ /media/MouthHealthy/Files/Kids_Section/ ADAPrimaryToothDev_Eng.pdf

Begzati, A, Berisha, M, Mrasori S., Latifi, BX, Prokshi, Haliti, Maxhuni, V, Hoxha, VH, dan Halimi, V, 2015, Early Childhood Caries (ECC) - Etiology, Clinical Consequences and Prevention, Emerging Trends in Oral Health Sciences and Dentistry (Edited Volume by Mandeep Singh Virdi), Open access peer-reviewed chapter in, dilihat 5 Maret 2019, https:// www.intechopen.com/books/emerging-trends-in-oral-health-sciences-and-dentistry/ early-childhood-caries-ecc-etiology-clinical-consequences-and-prevention.

Dooley D, Moultrie NM, Heckman B, Gansky SA, Potter MB, and Walsh MM., 2016, Oral Health Prevention and Toddler Well-Child Care: Routine Integration in a Safety Net System, Pediatrics 137(1): e20143532

Direktorat Jenderal Bina Upaya Kesehatan, 2012, Pedoman pemeliharaan kesehatan gigi dan mulut ibu hamil dan anak usia balita bagi tenaga kesehatan di fasilitas pelayanan kesehatan, Kementerian Kesehatan RI, Jakarta.

Kementerian Kesehatan Republik Indonesia, 2018, Potret Sehat Indonesia dari RISKESDAS 2018, dilihat 5 Maret 2019, http://www.depkes.go.id/article/print/18110200003/potretsehat-indonesia-dari-riskesdas-2018.html

Mouth Healthy, 2019, Teething, dilihat 6 Maret 2019, https://www.mouthhealthy.org/en/aztopics/t/teething

Nakre PD and Harikiran AG., 2013, Effectiveness of oral health education programs: A systematic review, J Int Soc Prev Community Dent 3(2): 103-115.

Scully, C, \& Welbury, R, 1994, Color Atlas of Oral Diseases in Children and Adolescents, Wolfe Publishing, Mosby. 